\title{
Diurnal and nocturnal drooling in Parkinson's disease
}

\author{
J. G. Kalf $\cdot$ B. R. Bloem $\cdot$ M. Munneke
}

Received: 16 March 2011/Revised: 29 May 2011/ Accepted: 6 June 2011/Published online: 23 June 2011

(C) The Author(s) 2011. This article is published with open access at Springerlink.com

\begin{abstract}
Drooling as symptom of Parkinson's disease (PD) has thus far been poorly defined. This uncertainty is reflected by high variations in published prevalence rates. The aim of this study was to investigate the prevalence of saliva loss versus accumulation of saliva as a possible preliminary stage, and diurnal drooling versus nocturnal drooling. In addition, we evaluated the association between drooling severity and the severity of facial and oral motor disorders. We collected age, disease duration, UPDRS III and Hoehn \& Yahr stage from 104 consecutive outpatients with PD. Diurnal and nocturnal drooling was evaluated with a validated questionnaire (ROMP-saliva). A speech pathologist, blinded for drooling severity, rated facial expression, involuntary mouth opening and difficulty with nose breathing and also interviewed patients about sleeping position and nose-breathing during the night. Thirty patients (29\%) had no complaints with saliva control ('nondroolers'), 45 patients (43\%) experienced accumulation of saliva or only nocturnal drooling ('pre-droolers'), and 29 (28\%) had diurnal drooling (24 of which also drooled
\end{abstract}

J. G. Kalf $(\bowtie)$

Nijmegen Centre for Evidence Based Practice,

Department of Rehabilitation, Radboud University Nijmegen

Medical Centre, Internal code 897, P.O. Box 9101,

6500 HB Nijmegen, The Netherlands

e-mail: h.kalf@reval.umcn.nl

B. R. Bloem

Donders Institute for Brain, Cognition and Behaviour, Centre for Neuroscience, Radboud University Nijmegen Medical Centre, Nijmegen, The Netherlands

\section{Munneke}

Nijmegen Centre for Evidence Based Practice, IQ Healthcare, Scientific Institute for Health Care, Radboud University Nijmegen Medical Centre, Nijmegen, The Netherlands during the night; 'droolers'). The droolers had longer disease duration ( 10 vs. 7 years, $p=0.01)$ and drooling was independently associated with involuntary mouth opening $(\mathrm{OR}=2.0 ; 95 \% \mathrm{CI} 1.02-3.99)$ and swallowing complaints $(\mathrm{OR}=1.2 ; 95 \%$ CI 1.03-1.31). Diurnal drooling—defined as dribbling of saliva while awake-is present in about $28 \%$ of PD patients. This is less than usually reported. Diurnal drooling typically appeared later in the disease course. The association with oral motor behavior should encourage the development of behavioral treatment approaches.

Keywords Parkinson's disease - Diurnal drooling · Nocturnal drooling

\section{Introduction}

Parkinson's disease (PD) is a common movement disorder characterized by motor and non-motor symptoms [3, 7, 17]. Oral motor problems such as dysarthria and dysphagia are frequently reported by PD patients. Drooling (or dribbling of saliva) is considered a related problem. In a metaanalysis based on 10 studies, we found that prevalence rates of drooling varied between 32 and $74 \%$, depending on disease severity and definition [9]. The pooled prevalence in community-dwelling PD patients was $56 \%$. However, many clinicians would feel that the prevalence rate is lower, because overt dribbling of saliva is relatively rarely seen in clinical practice. Complaints about saliva or drooling can be assessed subjectively, but questionnaires that include drooling such as SCOPA-AUT [21] and PD NMSQuest [14] rarely make a distinction between diurnal and nocturnal drooling. Moreover, little distinction is being made between awareness of saliva accumulating in the 
Table 1 MDS-UPDRS: 2.2 saliva and drooling [6]

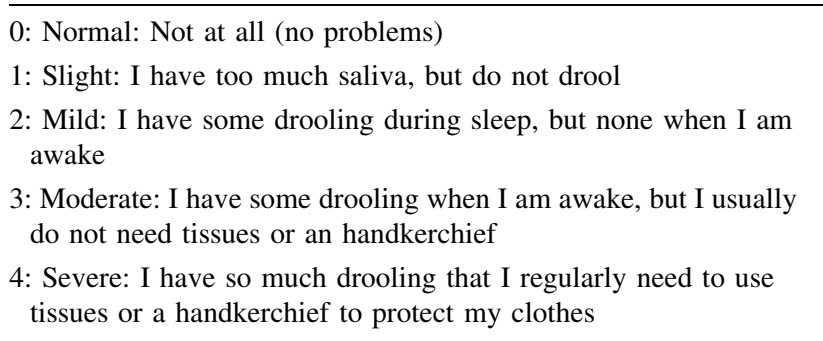

Table 2 Drooling severity scales (2 items from ROMP-saliva [8])

Do you experience loss of saliva during the day?
1. I do not experience loss of saliva during the day and I do not
feel increased amounts of saliva in my mouth either
2. I do not experience loss of saliva during the day but I do feel
increased amounts of saliva in my mouth
3. I experience saliva in the corners of my mouth or on my chin
4. I lose saliva on my clothes
5. I lose saliva on my clothes, but also on books or on the floor
Do you experience loss of saliva during the night?
1. I do not experience loss of saliva during the night at all
2. My pillow sometimes gets wet during the night
3. My pillow regularly gets wet during the night
4. My pillow always gets wet during the night
5. Every night my pillow and other bedclothes get wet

mouth versus actual loss of saliva from the mouth. These inconsistencies in how drooling was defined might explain why published prevalence rates vary so much.

There are no data on the prevalence of accumulation of saliva or nocturnal drooling versus diurnal drooling. Therefore, our first aim was to investigate the prevalence and distribution of diurnal and nocturnal drooling in a large cohort of community-dwelling PD patients. Second, we aimed to test the assumption that accumulation of saliva or mere nocturnal saliva loss is an intermediate phase leading up towards the most severe condition of diurnal drooling, as is expressed in the new MDS-UPDRS (Table 1) [6] and the Radboud Oral Motor inventory for Parkinson's disease (ROMP)-saliva (Table 2) [8]. Third, we aimed to extend our pilot observations that drooling is associated with facial and oropharyngeal akinesia and male gender [10].

\section{Methods}

A total of 104 consecutive community-dwelling outpatients with PD (according to the UK Brain Bank criteria) were included. Data on age, disease duration, UPDRS III, Hoehn \& Yahr stage were collected. All patients completed the Radboud Oral Motor inventory for Parkinson's disease
(ROMP) [8]. This is a validated questionnaire consisting of three domains: seven items with a 5-point scale for the domains 'speech' and 'swallowing' and nine items for the domain 'saliva control'. We used the scores on two items of the latter subscale to identify the presence and severity of diurnal and nocturnal drooling (Table 2). We then constructed three different severity groups following the Saliva \& Drooling subscale of the MDS-UPDRS (Table 1): 'non-droolers', i.e. patients without any complaints (score 0 ); 'pre-droolers', a term we suggest to use for patients who only experience accumulation of saliva or only nocturnal drooling (score 1 or 2); and 'droolers', meaning patients with diurnal drooling (loss of saliva from the mouth) with or without nocturnal drooling (score 3 or 4).

To investigate which oral and facial characteristics might be associated with drooling severity, an experienced speech pathologist (who was unaware of the patients' score on the ROMP) scaled three facial characteristics: the UPDRS subscale for facial expression; a scale focused on mouth opening; and a scale to score difficulty with nose breathing, as previously described [10]. In addition, to explore factors possibly related to nocturnal drooling severity, the speech pathologists asked patients and spouses whether the patients slept mainly on their side or mainly in the supine position, and also whether the patient breathed mainly through the nose or mainly through the mouth during sleeping. The rationale behind the last variable is that when the mouth is open, gravity directs the saliva flow into the pharynx while supine, but out of the mouth when lying sideways.

\section{Statistical analyses}

We used SPSS 16.0 for statistical analyses and $p$ values of $<0.05$ were considered significant. The hypothesis that the three groups differ considering disease characteristics and oral and facial parameters was tested with one-way ANOVA for numerical variables and the Kruskal-Wallis Test for ordinal and nominal variables. To explore factors that would best predict drooling, we compared the characteristics between the droolers versus the non-droolers $\&$ pre-droolers with independent $t$ tests for continuous variables, Mann-Whitney $U$ test for ordinal variables and chisquare for nominal variables. We then performed a multivariate analysis using forward logistic regression with drooling as the dependent variable and the significant disease characteristics and oral-facial scores (except ROMPsaliva) as independent variables.

\section{Results}

Of 104 patients, 30 patients (29\%) were non-droolers, 45 patients (43\%) pre-droolers, and $29(28 \%)$ were droolers 
Table 3 Distribution of diurnal and nocturnal drooling complaints

\begin{tabular}{lll}
\multicolumn{2}{l}{ Nocturnal drooling } \\
\hline No & Sometimes & $\begin{array}{l}\text { Regularly to } \\
\text { always } \\
(1)\end{array}$ \\
& $(2)$ & $(3-5)$
\end{tabular}

\begin{tabular}{llllr}
\hline Diurnal drooling & & & & \\
No (1) & $30^{\mathrm{a}}$ & $15^{\mathrm{b}}$ & $3^{\mathrm{b}}$ & 48 \\
Only accumulation & $11^{\mathrm{b}}$ & $10^{\mathrm{b}}$ & $6^{\mathrm{b}}$ & 27 \\
$(2)$ & & & & \\
Yes (3-5) & $5^{\mathrm{c}}$ & $14^{\mathrm{c}}$ & $10^{\mathrm{c}}$ & 29 \\
Total & 46 & 39 & 19 & 104 \\
\hline
\end{tabular}

Interpretation for classification in subgroups

${ }^{\text {a }}$ Group 1, No nocturnal or diurnal complaints (non-droolers)

${ }^{\mathrm{b}}$ Group 2, Accumulation of saliva or only nocturnal drooling (predroolers)

${ }^{\mathrm{c}}$ Group 3, Diurnal drooling with or without nocturnal drooling (droolers)

(of which 24 also had drooling during the night) (Table 3). Severe diurnal drooling (scores 4 or 5) was present in four patients (4\%), and in only two cases actual drooling was visible during consultation. Nocturnal drooling (with or without diurnal drooling) was present in 58\%, in 14 patients $(14 \%)$ regularly (score 3 ) and in five (5\%) every night and severe (score 4-5).
The distribution of disease characteristics and oral and facial parameters for the three subgroups is given in Table 4 . All disease characteristics and all facial, oral motor and sleeping parameters that may be associated with drooling show a trend of increasing difficulty. Differences between the three groups were significant except for age, difficulty with nose breathing and posture and breathing during sleep.

When comparing the non-droolers \& pre-droolers $(n=75)$ with the droolers $(n=29)$, droolers were older (68 vs. 62 years, $p=0.02$ ), had more severe PD (UPDRS III 31 vs. 27 points, $p=0.03$ ), longer disease duration 10 vs. 7 years, $p=0.01$ ), worse scores on dysphagia (ROMPswallowing 12 vs. 10 points; $p=0.01$ ), worse scores on facial expression ( 1.85 vs. $1.42, p=0.01)$ and more severe involuntary mouth opening (1.74 vs. $1.32 ; p=0.01)$. Men were equally present: $64 \%$ of non/pre-droolers and $69 \%$ of droolers $(p=0.63)$. Forward logistic regression with these variables identified involuntary mouth opening $(\mathrm{OR}=2.0$, 95\% CI 1.02-3.99) and dysphagia ( $\mathrm{OR}=1.2 ; 95 \% \mathrm{CI}$ $1.03-1.31)$ as the factors independently associated with drooling.

\section{Discussion}

We investigated the prevalence of diurnal and nocturnal drooling in a large cohort of community-dwelling

Table 4 Characteristics of subgroups

\begin{tabular}{|c|c|c|c|c|}
\hline & $\begin{array}{l}\text { Non-droolers: } \\
\text { no complaints }\end{array}$ & $\begin{array}{l}\text { Pre-droolers: accumulation of } \\
\text { saliva or only nocturnal drooling }\end{array}$ & $\begin{array}{l}\text { Droolers: diurnal drooling with } \\
\text { or without nocturnal drooling }\end{array}$ & $p$ value \\
\hline $\mathrm{N}(\%)$ & $30(29)$ & $45(43)$ & $29(28)$ & \\
\hline \multicolumn{5}{|l|}{ Patient characteristics } \\
\hline Gender ( $\%$ of men) & 37 & 82 & 69 & 0.000 \\
\hline Age (years; SD) & $62(10.2)$ & $62(10.3)$ & $68(9.4)$ & 0.069 \\
\hline UPDRS III (SD) & $24(10.7)$ & $28(9.9)$ & $31(9.8)$ & 0.019 \\
\hline \multicolumn{5}{|l|}{ Hoehn\&Yahr } \\
\hline Mild (1-2) (\%) & 60 & 42 & 31 & 0.044 \\
\hline Moderate $(2.5-3)(\%)$ & 37 & 53 & 62 & \\
\hline Severe $(4-5)(\%)$ & 3 & 5 & 7 & \\
\hline Disease duration (years; SD) & $6(4.9)$ & $7(4.6)$ & $10(5.4)$ & 0.010 \\
\hline ROMP-saliva control (7-35) ${ }^{\mathrm{a}}$ & $7(0.0)$ & $9(3.3)$ & $15(4.8)$ & 0.000 \\
\hline \multicolumn{5}{|l|}{ Facial and oral motor characteristics } \\
\hline ROMP-speech (7-35) & $11(4.2)$ & $15(5.1)$ & $16(5.7)$ & 0.002 \\
\hline ROMP-swallowing (7-35) & $9(2.6)$ & $10(3.9)$ & $12(4.4)$ & 0.006 \\
\hline Facial expression $(0-4)$ & $1(0-3)$ & $1(1-3)$ & $2(0-3)$ & 0.044 \\
\hline Mouth opening (1-4) & $1(1-3)$ & $1(1-3)$ & $2(1-3)$ & 0.010 \\
\hline Difficult nose breathing (1-4) & $1(1-2)$ & $1(1-3)$ & $1(1-3)$ & 0.137 \\
\hline \multicolumn{5}{|l|}{ Sleeping characteristics } \\
\hline Sleeping on one side $(\%)$ & 43 & 50 & 68 & 0.266 \\
\hline Breathing through the mouth $(\%)$ & 36 & 37 & 57 & 0.291 \\
\hline
\end{tabular}

a ROMP-saliva minus items 'day' and 'night' (see Table 2) 
outpatients with PD. Seventy-one percent of patients confirmed problems with saliva or drooling, which is roughly the prevalence that is usually cited in publications $[1,5,16$, 20]. However, here we demonstrate that actual diurnal drooling, i.e. dribbling of saliva from the mouth while awake, is reported by only $28 \%$ of PD patients. Among these, severe drooling (i.e. saliva loss on clothes or on the floor) was present in only four cases.

The prevalence rate of $28 \%$ seems more in accordance with everyday clinical practice than the overall rate of $56 \%$ that we estimated in a meta-analysis [9]. Furthermore, the present observations underline the importance of being unambiguous in drooling studies about how drooling is defined [9]. Nevertheless, drooling should not be trivialized as the physical, emotional and social consequences can have a major impact on everyday life $[2,11,13]$.

Our results confirm that saliva complaints increase with disease severity. We also provide new evidence that the experience of saliva accumulation or nocturnal drooling may precede complaints about actual dribbling of saliva, as stated by the Saliva \& Drooling subscale of the MDSUPDRS [6]. Furthermore, our data imply that drooling is generally not an early complaint, and that it takes an average of 3 years to develop diurnal drooling after the patient starts to feel accumulation of saliva or noted a wet pillow when waking up in the morning.

Accumulation of saliva suggests hypersalivation, but there is mounting evidence from sialometry studies that saliva production in PD patients is normal or even lower than in controls $[4,12,20]$. Experiencing accumulation or loss of saliva might then be caused by a reduced swallowing frequency. However, in our experience this is difficult to demonstrate when patients are overtly observed [10]. Specifically, we compared 15 droolers with 15 nondroolers (with exclusion of pre-droolers), and demonstrated that drooling was independently associated with hypomimia (including parted lips), which was in turn associated with dysphagia, disease severity, and male sex. In the current study, the same facial and oral motor factors were different between non-droolers, pre-droolers and droolers. Moreover, when comparing non-droolers/pre-droolers with droolers, mouth opening and dysphagia were the only factors independently associated with drooling, consistent with previous studies on the pathophysiology of drooling $[10,15,19]$. But men were similarly represented in both groups, so these results contradict our previous finding that drooling is more common in men than in women [10].

Nocturnal drooling has rarely been studied as a specific problem. In our cohort it was reported by $58 \%$ of patients, but in only $18 \%$ was it present regularly or every night. It remains important to evaluate nocturnal drooling, mainly in relation to concurrent diurnal complaints, or as a prelude to more severe diurnal drooling several years later. Five patients in group 3 lost saliva exclusively during the day, having no complaints during the night. One explanation may be their sleeping position, as one of these patients with most severe diurnal drooling (score 5) always slept on his back. This reduces the risk of nocturnal saliva loss, but at the same time may increase the risk of nocturnal aspiration of saliva, especially in severely affected patients with respiratory problems. Our results show a trend that sleeping on one side and with an open mouth facilitates nocturnal drooling. However, the reliability of these responses is doubtful. Obviously, only objective documentation with polysomnography would provide reliable data about position, breathing and saliva swallowing during sleep [18].

An overall limitation of this study is the reliability of several measures. The speech pathologist who assessed the patients was blinded with respect to drooling status, but was expected to do a full exam, so observation bias cannot be ruled out. Second, our centre is a dedicated referral centre for patients with PD, and this may have caused referral bias. However, the basic characteristics of our study population are comparable with other studies on home-living PD patients with respect to age (mean 64 years), disease severity (mean UPDRS III score; median Hoehn \& Yahr stage 2.5, range 1-5) and disease duration (8 years). This is probably because our center also attracts large numbers of uncomplicated patients, not just patients with advanced PD.

In conclusion, diurnal drooling defined as dribbling of saliva while awake is present in about $28 \%$ of communitydwelling PD patients. Drooling may be preceded by the awareness of saliva accumulation and nocturnal drooling, and is associated with involuntary mouth opening and swallowing complaints. These findings should encourage the development of behavioral treatment approaches for drooling in PD.

Conflict of interest The authors declare that they have no conflict of interest.

Open Access This article is distributed under the terms of the Creative Commons Attribution Noncommercial License which permits any noncommercial use, distribution, and reproduction in any medium, provided the original author(s) and source are credited.

\section{References}

1. Arbouw ME, Movig KL, Koopmann M, Poels PJ, Guchelaar HJ, Egberts TC, Neef C, van Vugt JP (2010) Glycopyrrolate for sialorrhea in Parkinson disease: a randomized, double-blind, crossover trial. Neurology 74:1203-1207

2. Bloem BR, Kalf JG, van de Kerkhof PC, Zwarts MJ (2009) Debilitating consequences of drooling. J Neurol 256:1382-1383

3. de Lau LM, Giesbergen PC, de Rijk MC, Hofman A, Koudstaal PJ, Breteler MM (2004) Incidence of Parkinsonism and Parkinson 
disease in a general population: the Rotterdam Study. Neurology 63:1240-1244

4. Del Tredici K, Hawkes CH, Ghebremedhin E, Braak H (2010) Lewy pathology in the submandibular gland of individuals with incidental Lewy body disease and sporadic Parkinson's disease. Acta Neuropathol 119:703-713

5. Dogu O, Apaydin D, Sevim S, Talas DU, Aral M (2004) Ultrasound-guided versus 'blind' intraparotid injections of botulinum toxin-A for the treatment of sialorrhoea in patients with Parkinson's disease. Clin Neurol Neurosurg 106:93-96

6. Goetz CG, Tilley BC, Shaftman SR, Stebbins GT, Fahn S, Martinez-Martin P, Poewe W, Sampaio C, Stern MB, Dodel R, Dubois B, Holloway R, Jankovic J, Kulisevsky J, Lang AE, Lees A, Leurgans S, LeWitt PA, Nyenhuis D, Olanow CW, Rascol O, Schrag A, Teresi JA, van Hilten JJ, LaPelle N (2008) Movement Disorder Society-sponsored revision of the Unified Parkinson's Disease Rating Scale (MDS-UPDRS): scale presentation and clinimetric testing results. Mov Disord 23:2129-2170

7. Jankovic J (2008) Parkinson's disease: clinical features and diagnosis. J Neurol Neurosurg Psychiatry 79:368-376

8. Kalf JG, Borm GF, Swart de BJM, Bloem BR, Zwarts MJ, Munneke M (2011) Reproducibility and validity of patients-rated assessment of speech, swallowing and saliva control in Parkinson's disease. Archives of Physical Medicine and Rehabilitation (in press)

9. Kalf JG, de Swart BJM, Borm GF, Bloem BR, Munneke M (2009) Prevalence and definition of drooling in Parkinson's disease: a systematic review. J Neurol 256:1391-1396

10. Kalf JG, Munneke M, Engel-van den Hoek L, de Swart BJ, Borm GF, Bloem BR, Zwarts MJ (2011) Pathophysiology of diurnal drooling in Parkinson's disease. Movement Disorders Apr 11 [Epub ahead of print]

11. Kalf JG, Smit AM, Bloem BR, Zwarts MJ, Munneke M (2007) Impact of drooling in Parkinson's disease. J Neurol 254:12271232
12. Kusbeci OY, Koken T, Demirbas H, Koca B (2009) Sialorrhea and salivary composition in patients with Parkinson's disease. J Neurol Sci [Turkish] 26:264-270

13. Leibner J, Ramjit A, Sedig L, Dai Y, Wu SS, Jacobson C, Okun MS, Rodriguez RL, Malaty IA, Fernandez HH (2010) The impact of and the factors associated with drooling in Parkinson's disease. Parkinsonism Relat Disord 16:475-477

14. Martinez-Martin P, Schapira AH, Stocchi F, Sethi K, Odin P, Macphee G, Brown RG, Naidu Y, Clayton L, Abe K, Tsuboi Y, Macmahon D, Barone P, Rabey M, Bonuccelli U, Forbes A, Breen K, Tluk S, Olanow CW, Thomas S, Rye D, Hand A, Williams AJ, Ondo W, Chaudhuri KR (2007) Prevalence of nonmotor symptoms in Parkinsons disease in an international setting; study using nonmotor symptoms questionnaire in 545 patients. Mov Disord 22:1623-1629

15. Nobrega AC, Rodrigues B, Torres AC, Scarpel RD, Neves CA, Melo A (2008) Is drooling secondary to a swallowing disorder in patients with Parkinson's disease? Parkinsonism Relat Disord 14:243-245

16. Postma AG, Heesters M, van LT (2007) Radiotherapy to the salivary glands as treatment of sialorrhea in patients with Parkinsonism. Mov Disord 22:2430-2435

17. Samii A, Nutt JG, Ransom BR (2004) Parkinson's disease. Lancet 363:1783-1793

18. Sato K, Nakashima T (2006) Human adult deglutition during sleep. Ann Otol Rhinol Laryngol 115:334-339

19. Tsuboi Y, Umemoto T, Kikuta T, Yamada T (2009) Tongue bradykinesia is related to severity of drooling in Parkinson's disease. Parkinsonism Relat Disord 15:S71-S72

20. Tumilasci OR, Cersosimo MG, Belforte JE, Micheli FE, Benarroch EE, Pazo JH (2006) Quantitative study of salivary secretion in Parkinson's disease. Mov Disord 21:660-667

21. Verbaan D, Marinus J, Visser M, van Rooden SM, Stiggelbout AM, van Hilten JJ (2007) Patient-reported autonomic symptoms in Parkinson disease. Neurology 69:333-341 